\title{
METODOLOGIAS ATIVAS DE ENSINO E APRENDIZAGEM: UMA EXPERIÊNCIA COM DOCENTES DA EDUCAÇÃO BÁSICA
}

\author{
Active Methodologies Of Teaching And Learning: An Experiment With Teachers The Basic \\ Education
}

Antônio Eustáquio Ferreira ${ }^{1}$

Resumo: Relato com o objetivo de descrever a experiência de um curso de formação continuada de professores, cujo título é Metodologias Ativas de Ensino e Aprendizagem: uma experiência com docentes da educação básica, desenvolvido em parceria com a Universidade Federal da Grande Dourados, sob a coordenação e execução do autor. Os resultados evidenciaram que o contato dos docentes da educação básica com algumas técnicas das Metodologias Ativas de Ensino e Aprendizagem provocam reflexões sobre suas atitudes e o seus papeis diante de um cenário desafiador, cujos estudantes têm acesso a um número sem limites de informações. $\mathrm{O}$ modelo utilizado teve como estratégia de ensino-aprendizagem o próprio método das Metodologias Ativas, caracterizado por colocar o estudante em contato com as técnicas, visando um ensino efetivamente comprometido com a aquisição de competências, habilidades e conhecimentos de modo que eles, os estudantes ou cursistas no caso possam ser atores críticos, reflexivos, transformadores da realidade, dos problemas que se apresentam. Os cursistas professores puderam repensar sobre seus deveres éticos para com a sociedade, revisando suas práticas de ensino-aprendizagem e modelos de avaliações.

Palavras-Chave: Metodologias de Aprendizagem, Formação de professores, Métodos e Técnicas de ensino.

Abstract: Report of experience in order to describe the development of a continuing education course for teachers, whose tittle is: Active Methodologies of Teaching and Learning: an experiment with teachers the basic education. Developed in partnership with the Federal University of Grande Dourados under the coordination and execution of the author. The results showed that the contact of

\footnotetext{
${ }^{1}$ Universidade Federal da Grande Dourados , Professor Visitante no Programa de Pós-graduação - Faculdade de Educação - FAED - E-mail: eustaquioaf@gmail.com-antonioferreira@ufgd.edu.br
} 
the basic education teachers with some techniques of Active Methods of Teaching and Learning provoked reflections on their attitudes and their roles before a challenging scenario, whose students have access to a number limitless of information. The model used was a teaching and learning strategic of the active methodologies, characterized by placing the student in touch with the techniques, seeking a teaching effectively committed to the acquisition of skills, abilities and knowledge so that they, students or course participants or in the event, become actors reflective, reality transformers, and of the problems that arise. Was used teaching and learning strategy with method itself of Active methodologies. The course participants teachers can rethink their ethical duties to the society, revising their teachings, practices and assessments models.

Key words: Learning methodologies, Teacher, Teaching methods and techniques. 


\section{Introdução}

O presente relato é resultado de experiência com projeto de pesquisa em andamento na Escola Estadual Ministro João Paulo dos Reis Veloso, situada na cidade de Dourados-MS, a qual teve início em fevereiro de 2016, coincidindo com início das atividades do ano letivo. Convidado para ministrar palestras sobre aspectos pedagógicos na referida escola, tive a oportunidade de entrar em contato com a realidade daquele ambiente. Houve o envolvimento em ações desenvolvidas em parcerias com o Estado, tais como programa "Encontro com Familiares: um diálogo sobre os adolescentes", do qual participei como palestrante nas quatro etapas para entrega de cartilhas destinadas aos familiares dos estudantes da Escola. Assim sendo, percebemos tratar-se de campo propício ao desenvolvimento de projetos tanto de pesquisas, quanto de extensão. $\mathrm{O}$ projeto de pesquisa que se encontra em andamento, cujo título é "História dos relacionamentos entre pai e filho (a), nos discursos de mães de crianças e adolescentes escolares: reflexo na sociabilidade violenta", terá por objetivo colaborar com a compreensão de fatores que se refletem na falha da função paterna, como a "morte dos nomes-do-pai" nos discursos das mães, como se relacionam com a sociabilidade violenta em crianças e adolescentes escolares. $\mathrm{O}$ suporte fundamental do empreendimento será constituído pela psicanálise em situações sociais críticas cujo instrumento será a utilização de grupo focal para coleta de dados e análise de discurso. O projeto de extensão idealizado teve como título Metodologias Ativas de Ensino e Aprendizagem: uma experiência com docentes da educação básica.

\section{A Escola}

A Escola Estadual Ministro João Paulo dos Reis Veloso será palco de experiência de ensino em tempo integral a partir do ano de 2017. Assim sendo, propomos um curso de formação, que deve ser continuada para os docentes da escola e que poderá contribuir para o enriquecimento do processo de ensino e aprendizagem, por se tratar de proporcionar aos professores um contato com algumas técnicas das Metodologias Ativas de Ensino e Aprendizagem. A contextualização do curso poderá ser encontrada nos eixos temáticos do Projeto Político-Pedagógico da Escola Estadual Ministro João Paulo dos Reis Veloso, (Governo do Estado do Mato Grosso do Sul - ESMPRV, 2016), em seus itens: 3 Missão: de "assegurar um ensino de qualidade garantindo o acesso e a permanência dos alunos na escola, formando cidadãos críticos 
capazes de agir na transformação da sociedade, incentivando a criatividade e o respeito ao próximo.”; 4 Visão: Ser "uma escola de referência no município de Dourados - MS, pela qualidade que oferecemos, pelo atendimento aos pais e alunos, primando pela transparência, respeito pelo indivíduo, procurando parcerias que valorizem e desenvolvam a criatividade e competência técnico-científica."; e 5 Valores: "Considerando a evolução intelectual e tecnológica do indivíduo: Buscamos excelência na qualidade da educação desenvolvida nesta unidade escolar, proporcionando um atendimento de qualidade em todos os segmentos, respeitando a individualidade e o coletivo da comunidade. Valorizando o trabalho em parceria, considerando o nosso parceiro como colaborador no processo. Respeitamos a dignidade e os direitos de cada pessoa. Apoiamos a criatividade e a inovação individual e coletiva". Nesse sentido, outras características do Projeto da Escola Estadual Ministro João Paulo dos Reis Veloso também se relacionam com a proposta em questão, quais sejam:

A escola atende crianças, adolescentes e adultos de bairros periféricos de distritos da reserva indígena e adjacências. Pessoas de classe média baixa e baixa. Algumas com sérios conflitos familiares e trabalhistas.

A Escola Estadual Ministro João Paulo dos Reis Veloso pretende proporcionar o desenvolvimento do processo educativo e a formação integral do educando, despertando o senso crítico, resgatando os valores humanos, respeitando as diferenças e preparando cada indivíduo para o exercício pleno da cidadania, sendo agente de transformação da sociedade.

Criada pelo Decreto número 1.583, em 08/08/1973, a Escola Estadual Ministro João Paulo dos Reis Veloso atende a 1.407 alunos, sendo 509 no Ensino Médio; possui 147 funcionários: 41 professores efetivos e 16 convocados.

Esta proposta também tem interface com a Missão, Objetivo Institucional, Objetivos Específicos e se insere no contexto da chamada do Projeto Político-Pedagógico de resgatar valores em busca da cidadania, pois este visa permitir à comunidade escolar vivenciar experiências reais do desempenho da cidadania através do conhecimento e prática de valores éticos, morais e legais. Ocorre conexão entre as propostas no eixo do Projeto Político- Pedagógico da Escola Estadual Ministro João Paulo dos Reis Veloso de projetos específicos, Projeto Interdisciplinar vivendo valores, cujo público alvo será todos os colaboradores da escola e a 
comunidade, objetivando alcançar qualidade salutar de vida, pela interação harmônica na convivência em grupo.

O objetivo do curso de Metodologias Ativas de Ensino e Aprendizagem é proporcionar o acesso, reflexões e práticas das principais técnicas das Metodologias para docentes da educação básica da Escola e também disponibilizar para as demais instituições educacionais da Grande Dourados. Discutir sobre a importância dos recursos e técnicas das Metodologias Ativas de Ensino e Aprendizagem, e também sobre o papel docente no processo de ensinoaprendizagem na educação básica. Visto que as práticas docentes atuais tem sido alvo de bastantes questionamentos, tentar provocar uma aproximação compreensiva dos professores da rede municipal e estadual, dentre outras da Grande Dourados para a importância das MAEA também no ensino básico. Para tanto, fez-se necessária a experiência com o curso. Para que pudéssemos acessar as reais funcionalidades das práticas e didáticas docentes hoje utilizadas. Portanto, o contexto atual é propício para apresentarmos as principais técnicas das Metodologias Ativas de Ensino e Aprendizagem que sirvam como recurso didático base para uma formação crítica e reflexiva dos estudantes. Quanto aos professores, que pudessem leva-los a uma revisão de suas atuações em seu cotidiano de planejamento, ações formas de avaliações.

\section{O Curso e as Metodologias Ativas de}

\section{Ensino e Aprendizagem}

$\mathrm{O}$ curso tem como foco a formação continuada de professores da educação básica na Grande Dourados, tendo em vista que haverá modificação em algumas escolas da cidade, a partir o ano de 2017, cujas propostas pedagógicas incluem estudos em período integral. Nesse sentido, o curso e a formação continuada de professores proporcionará o acesso a habilidades e competências para que eles, os professores atuem em sintonia com o novo modelo de ensino e aprendizagem.

Os aprendizes da atualidade são indivíduos que têm acesso a uns cem números de informações. Portanto, para que sejam motivados e seduzidos a participar de seu desenvolvimento escolar é crucial para os docentes tentar entende-los e investir em um modelo pedagógico que lhes permita empreender uma forma de ensinar e aprender de modo coletivo, participativo e desafiador, que provoque o senso crítico, criativo em ambos os atores do processo.

As Metodologias Ativas de Ensino e Aprendizagem, com seu conjunto de técnicas estimulam os processos construtivos de ação- 
reflexão-ação, com base na pedagogia de Paulo Freire, na qual o estudante deve ter uma postura ativa no percurso de seus estudos. Assim sendo, é oportuno que ele, o estudante seja desafiado a pesquisar e a descobrir soluções que se apliquem problemática da realidade. O papel do professor será o de estimular o aluno a buscar o conhecimento, a criar gosto pelo saber. Portanto, as Metodologias Ativas de Ensino e Aprendizagem, com suas técnicas que permitam ações transformadoras da realidade pelos professores e alunos, poderão promover a formação de indivíduos com condições de atuação crítica, reflexiva e autônoma na sociedade.

Berbel (2011) enfatiza que é consenso entre pesquisadores de educação de que há limitações na formação de crianças, jovens e adultos de modo que esta lhes proporcione participar "de modo integrado e efetivo da vida em sociedade" (BERBEL, 2011, p. 25). Há carência de seres humanos que sejam capazes de atitudes transformadoras em relação à problemática do meio em que vivem. A autora alerta que a legislação brasileira sinaliza para que a escola seja o agente que promova uma educação voltada para o desenvolvimento do estudante, de modo que ele adquira condições de também ser agente transformador na sociedade.
Segundo Berbel (2011) a escola deve atuar "para promover o desenvolvimento humano, a conquista de níveis complexos de pensamento e de comprometimento em suas ações". BERBEL, 2011, P. 26).

Já Zabala (1999) contribui para o tema discutindo o que ele denomina de "conteúdos procedimentais", que seria o conjunto de "aprendizagens que responde à pergunta": "O que se deve ensinar? Qual seria o papel do professor e da escola? (ZABALA, 1999, p. 7). O mesmo autor enfatiza o aspecto de como ensinar, mas alertando sobre os modelos de avaliação, demonstrando que não é apenas a quantificação de atividades, ele aponta a relevância da autoavaliação, em fornecer aos alunos alguns critérios que possam lhes proporcionar a autoavaliação, e também como os gestos, até mesmo enquanto processos inconscientes podem ser entendidos como instrumentos de avaliação. Zabala (1999) alerta sobre o olhar, um gesto, enfim expressões que podem ser interpretadas pelos alunos como alento, confiança ou recusa, que tudo imprime nas crianças, jovens e adultos um sinal de aprovação ou reprovação. Zabala (1999) também problematiza o tipo de ensino baseado em memorização de conhecimentos. Traz a noção de ensino por competências. Explicita que entende por competência a oportunidade de equacionamento de uma 
educação que possibilite ao estudante aplicar os conhecimentos adquiridos por competência na vida real. A educação deve instrumentalizar o estudante para que ele possa "responder aos problemas aos quais será exposto ao longo da vida". (ZABALA; ARNAU, 2010, p. 11). Portanto, percebemos que uma discussão, em um curso de formação continuada de professores, sobre a utilização das principais técnicas das Metodologias Ativas de Ensino e Aprendizagem, possa contribuir de modo significativo para a autonomia dos estudantes, além de constante revisão da atuação dos professores. É importante ressaltar também a possibilidade de potencialização da área pedagógica, como afirma Berbel (2011). E ainda, como nos ensina Berbel (2011), potencializar a área pedagógica de modo que os estudantes ou no caso, os cursistas se percebam "autônomos em suas interações" no curso (BERBEL, 2011, p. 26). Avaliar cada atividade de modo que um percentual entre quarenta e setenta por cento da turma tenham condições de avançar de modo salutar nos estudos.

Gemignani (2012) também contribui para nossa reflexão nos lembrando que o desafio do século é encontrarmos formas de ensinar para que os aprendizes adquiram habilidades, competências e atitudes para transformar a realidade de modo humanizado. Para tanto, deveremos considerar o contexto e a formação de professores, as Diretrizes Curriculares Nacionais, as constantes alterações no mercado de trabalho e o tipo de profissionais que ele exige.

Valendo-se de MEC (BRASIL, 2002) e Afrânio Cateni, João Oliveira e Luiz Dourado (2002), Gemignani (2012) chama a atenção, que o primeiro enfatiza questões sobre as alterações curriculares que reclamam flexibilidades. Então há urgência de ações para adaptação nesse mundo em constante movimento. Os segundos autores demonstram a importância da formação de novos profissionais lembrando mais uma vez que devem ser criativos, críticos, que tenham capacidade de entender e modificar os problemas que os desafiam. Nesse sentido, Sant'anna (1995) nos lembra da prática escolar libertadora, cuja característica é libertar o estudante dos medos: de errar, de ser, de viver. (SANT’ANNA, 1995, p. 9).

$$
\text { O artigo } 207 \text { da Constituição }
$$

Brasileira dispõe que "as universidades [...] obedecerão ao princípio da indissociabilidade entre ensino, pesquisa e extensão". Equiparadas, essas funções básicas merecem igualdade em tratamento por parte das instituições de ensino superior. No cenário atual as universidades são lugares de debates com destaque para as questões ligadas ao 
ensino, à pesquisa e à extensão. Uma articulação entre esse tripé deve sinalizar para uma formação que leve em consideração os problemas da sociedade. O curso de Metodologias Ativas de Ensino e Aprendizagem para docentes da educação básica, como projeto de extensão da Universidade Federal da Grande Dourados se encaixa no cenário atual, cuja discussão sobre o papel da instituição pública de educação se encontra em curso. A Lei de Diretrizes e Bases da Educação Nacional, as Diretrizes Curriculares Nacionais do Curso de Medicina e o Sistema Único de Saúde convidam os cursos da área de saúde a modificar algumas de suas práticas pedagógicas convencionais. Nesse sentido, promover uma formação continuada de professores da educação básica significa proporcionar a equiparação das funções também básicas do tripé: ensino, pesquisa e extensão, além da oportunidade em se antecipar quesito para enquadramento no que a legislação também deve propor para os demais cursos superiores, e também preparar os 'novos' estudantes incentivando hábitos que lhes proporcionem mais autonomia no percurso da educação superior.
Apresento uma fotografia do desenvolvimento das atividades como ilustração e embasamento (figura 1):

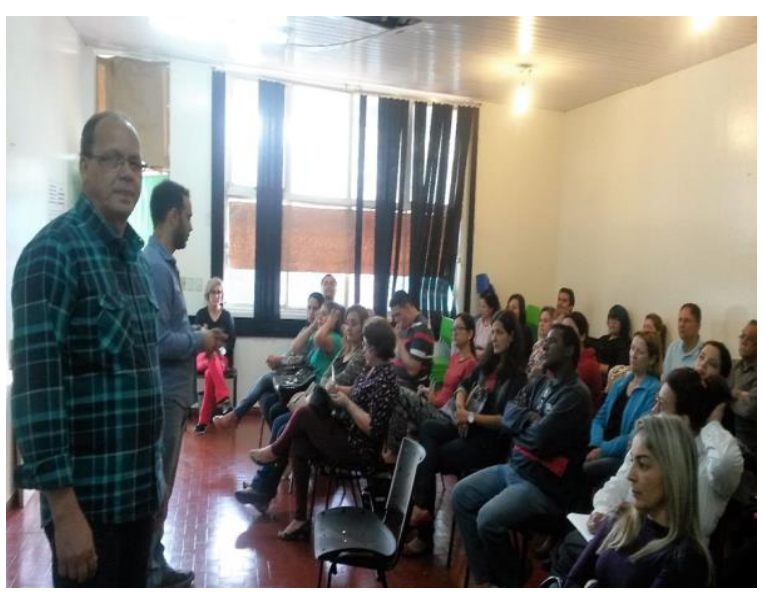

Figura 1. Desenvolvimento das atividades.

Apresentação do programa e início das atividades. Breve percurso histórico da utilização das Metodologias Ativas de Ensino e Aprendizagem no Brasil. Voltamos com ideias de Berbel (2011) quando explicita a técnica da problematização com o arco de Maguerez. Exploramos as ideias de Bordenave e Pereira (1982), citados por Berbel (2011), demonstrando as cinco etapas para utilização do Arco de Maguerez: 1) observação da realidade e definição de um problema; 2) pontos-chave; 3) teorização; 4) hipóteses de solução e 5) aplicação à realidade. Vale consultarmos as explicitações de Gemignani (2012), acerca das cinco etapas: 


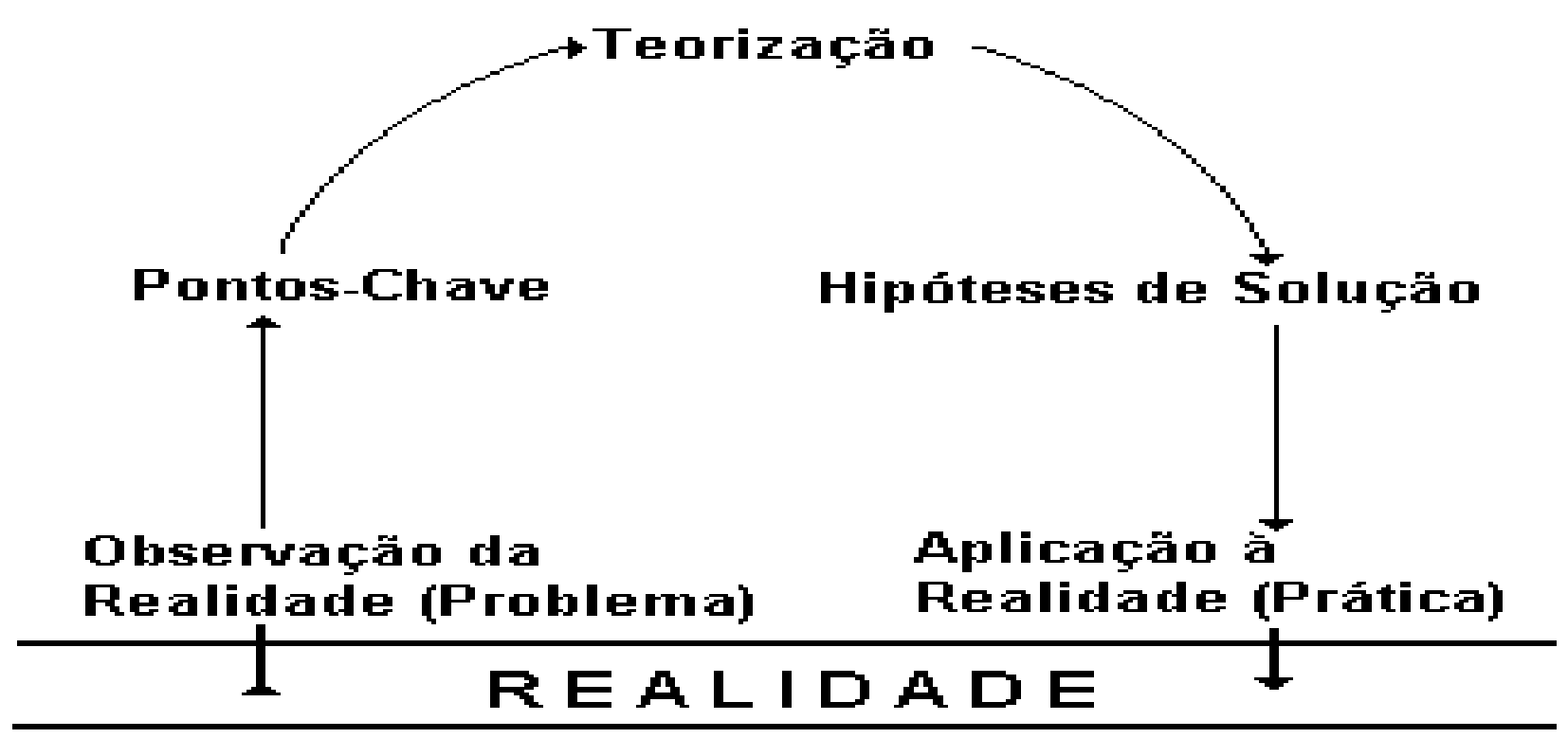

Figura 2. Esquema demonstrando as cinco etapas para utilização do Arco de Maguerez .

Hipóteses de Solução - individualmente

Sistematização das cinco etapas (figura 2):

Observação da realidade - o grupo analisa e discute o seu nível de conhecimento sobre o assunto observado; identifica aquilo que na realidade está inconsistente, preocupante, problemático.

Pontos-Chave - neste momento, é feita uma síntese do que é importante investigar sobre o problema, visando à transformação da realidade.

Teorização - os elementos do grupo checam o que já sabem e analisam o que precisam saber para pesquisar a resposta aos problemas levantados. buscam as fontes de informações que darão subsídios às propostas de suas hipóteses.

Aplicação à Realidade - voltam ao grupo para trocar informações e organizar o conhecimento adquirido, aplicam ou propõem intervenções na realidade e socializam o resultado para outros sujeitos. (GEMIGNANI, 2012, p. 7).

Em seguida trabalhamos com Aprendizagem Baseada em Problemas, do termo em inglês Problem Based Learning PBL. Inicialmente utilizada no Brasil em cursos de medicina. Nessa modalidade, segundo Berbel (2011) o estudante deve ser desafiado com problemas de modo que possa 
"aprender determinados conteúdos. "; acessar situações que provoquem "o especialista a determinar quais conhecimentos são necessários adquirir" (BERBEL, 2011, p. 32) para cada uma das situações.

Finalizamos trazendo algumas características da pesquisa científica. Já que a Escola Reis Veloso é parceira da Universidade Federal da Grande Dourados, nas questões relativas a estágios e projetos, estimulando os docentes e estudantes para que participem mais ativamente das pesquisas e projetos em andamento naquele ambiente.

\section{Considerações Finais}

Percebemos que a metodologia de aprendizagem, a apresentação de algumas técnicas no curso de formação continuada com docentes da educação básica produziram um impacto na maneira como os participantes percebiam o processo de ensino e aprendizagem e suas estratégias didáticas e técnicas de ensino. Sendo assim, possibilitou mais uma resposta para reflexão e enriquecimento dos procedimentos cotidianos dos professores participantes. Estes muitas vezes ansiosos por propostas educacionais transformadoras. O acesso às técnicas das Metodologias Ativas de Ensino e Aprendizagem também promove e revela uma aproximação compreensiva da necessidade de que um educador, um transformador social seja um profissional de excelência, consciente de sua função de liderança na sociedade.

\section{Referências Bibliográficas}

BERBEL, N. A. N.. As metodologias ativas e a promoção da autonomia de estudantes. Disponível em: http://www.proiac.uff.br/sites/default/files/documentos/berbel_2011.pdf. Acesso em 23 set. 2016.

BORDENAVE, J.D. ; PEREIRA, A.M. Estratégias de Ensino-Aprendizagem. 28 ed. Rio de Janeiro: Vozes, 2008.

CATANI, A.M.; OLIVEIRA, J.F.; DOURADO, L.F. Política Educacional, Mudanças no mundo do Trabalho e reforma curricular dos cursos de graduação no Brasil. Educação \& Sociedade. Campinas: Cedes, ano XXII, n. 75, p. 67-82, ago. 2001.

FREIRE, $P$. Pedagogia da autonomia: saberes necessários à prática educativa. $25^{\mathrm{a}}$ edição. São Paulo: Paz e Terra, 1996. Disponível em:

file:///C:/Users/UFGDFAED/Downloads/Pedagogia\%20da\%20Autonomia\%20-

\%20Paulo\%20Freire.pdf. Acesso em 23 set. 2016. 
GEMIGNANI, E Y M Y. Formação de professores e metodologias ativas de ensino aprendizagem: ensinar para a compreensão. Fronteiras da Educação [online], Recife, v. 1, n. 2, 2012. Disponível em: <http://www.fronteirasdaeducacao.org/index.php/fronteiras/article/view/14>. ISSN 2237-9703.

GOVERNO DO ESTADO DO MATO GROSSO DO SUL SECRETARIA DE ESTADO DE EDUCAÇÃO. Escola Estadual Ministro João Paulo dos Reis Veloso. Projeto Político-Pedagógico. Disponível em: http://www.sistemas.sed.ms.gov.br/ProjetoPoliticoPedagogico/Consultar.aspx. Acesso em 21 Jul. 2017.

MINISTÉRIO DA EDUCAÇÃO - MEC. RESOLUÇÃO CNE/CP No 1, de 18 de Fevereiro de 2002. Disponível em: http://portal.mec.gov.br/seesp/arquivos/pdf/res1_2.pdf. Acesso em 21 jul. 2017.

SANT'ANNA, I M. Por que avaliar? : como avaliar? : critérios e instrumentos. Petrópolis. Rio de Janeiro: Vozes, 1995.

ZABALA, A (Org.). Como trabalhar os conteúdos procedimentais em aula. Tradução Ernani Rosa. Porto Alegre: Editora Artes Médicas Sul Ltda. 1999.

ZABALA; ARNAU, A.; L.. Como aprender e ensinar competências. Porto Alegre: Artmed, 2010. 